\title{
Association study between immune-related miRNAs and mixed connective tissue disease
}

\author{
Barbara Stypińska ${ }^{1 *}$, Aleksandra Lewandowska², Anna Felis-Giemza², Marzena Olesińska² and \\ Agnieszka Paradowska-Gorycka'
}

\begin{abstract}
Background: Mixed connective tissue disease (MCTD) is a rare condition that is distinguished by the presence of specific U1-RNP antibodies. Information about its etiopathology and diagnostics is still unclear. miRNAs such as miR146, miR-155, and miR-143 emerged as key regulators of the immune system, known to be involved in the development of autoimmune diseases and cancers. We performed an association study between immune-related miRNAs and MCTD severity and susceptibility.

Methods: A total of 169 MCTD patients and 575 healthy subjects were recruited to the case-control study. The miRNA polymorphisms were genotyped using TaqMan SNP genotyping assay. TNF-a, IL-6, and IFN- $\gamma$ levels in serum were determined using ELISA. qRT-PCR of TRAF6, IRAK1, and microRNAs was performed using Taqman miRNA assays and TaqMan Gene Expression Assays.

Results: miR-146a rs2910164 G allele and GG genotype as well as miR-143 rs713147 A allele were more frequent in healthy subjects than in MCTD patients. miR-146a rs2910164 CC genotype and miR-143 T-rs353299*T-rs353291*Trs713147*G-rs353298 and C-rs353299*C-rs353291*T-rs713147*A-rs353298 haplotypes were associated with MCTD susceptibility. miR-146a rs2910164 C/T was associated with scleroderma and lymphadenopathy. miR-143 rs353299 $\mathrm{C} / \mathrm{T}$ was associated with swollen fingers or hands, the presence of enlarged lymph nodes, and pericarditis/pleuritis. miR-143 rs353298 A/G was associated with the occurrence of pericarditis/pleuritis and scleroderma. miR-143 rs353291 T/C showed association with pericarditis/pleuritis. The serum TNF-a, IFN- $\gamma$, and IL-6 levels were significantly higher in MCTD patients compared to healthy subjects. miR-143 SNPs were associated with higher proinflammatory cytokine concentration in serum only in healthy controls. IRAK1 and TRAF6 expression were higher in the MCTD patients compared to controls.
\end{abstract}

Conclusions: The results of our case-control study indicate the possible significance of miR-146a and miR-143/145 in the susceptibility and clinical picture of MCTD.

Keywords: MCTD, MicroRNA, Single-nucleotide polymorphisms, SNPs, Pathogenesis, Epigenetics

\footnotetext{
*Correspondence: barbara.stypinska@wp.pl

'Department of Molecular Biology, National Institute of Geriatrics, Rheumatology, and Rehabilitation, Spartańska 1, 02-637 Warsaw, Poland

Full list of author information is available at the end of the article
}

(c) The Author(s). 2021 Open Access This article is licensed under a Creative Commons Attribution 4.0 International License, which permits use, sharing, adaptation, distribution and reproduction in any medium or format, as long as you give appropriate credit to the original author(s) and the source, provide a link to the Creative Commons licence, and indicate if changes were made. The images or other third party material in this article are included in the article's Creative Commons licence, unless indicated otherwise in a credit line to the material. If material is not included in the article's Creative Commons licence and your intended use is not permitted by statutory regulation or exceeds the permitted use, you will need to obtain permission directly from the copyright holder. To view a copy of this licence, visit http://creativecommons.org/licenses/by/4.0/ The Creative Commons Public Domain Dedication waiver (http://creativecommons.org/publicdomain/zero/1.0/) applies to the data made available in this article, unless otherwise stated in a credit line to the data. 


\section{Introduction}

Autoimmunity, an abnormal response of the body to its own tissue antigens, is manifested in many ways that are categorized into various types of diseases depending on the tissue and antigen targeted. Mixed connective tissue disease (MCTD) is a rare disease entity that belongs to the so-called overlap syndromes. This means that it meets the diagnostic criteria for more than one autoimmune connective tissue disease (ACTD). MCTD combines the mild symptoms of systemic lupus erythematosus (SLE), systemic sclerosis (SSc), polymyositis/ dermatomyositis (PM/DM), and rheumatoid arthritis (RA) with the increased titer of U1snRNP antibodies [1, 2]. Due to the controversy associated with this disease, there are no diagnostic criteria for MCTD, approved by ACR. However, there are several diagnostic criteria for this disease in the literature, published by Sharp, Alarcón-Segovia, Kasukawa, and Kahn [1]. The high titer of ANA and U1-RNP are the first clue in the diagnosis of MCTD (in the absence of other specific antibodies) [1, 2]. Scientific research on MCTD patients allows to answer the question about the differences and similarities in pathogenesis of MCTD compared to other ACTDs. Greater knowledge on this subject will allow to unequivocally state if MCTD is a separate disease entity. It will facilitate diagnosis and treatment of patients who at the moment cannot be assigned to any existing ACTD.

The exact cause for immune system dysregulation and chronic inflammation is ambiguous. A significant step in understanding the processes regulating the proper functioning of the immune system was the discovery of the microRNA (miRNA). miRNAs regulate the immune system and the immune response. Specific miRNAs modulate antigen presentation, clonal selection, Th skewing, Treg function, cytokine production, cytokine functions, recruitment of chemo-dependent inflammatory cells, antibody production, and non-immune cell mechanisms of tissue damage [3-5]. Diseases with the autoimmune background are characterized by altered miRNA expression patterns which are able to exacerbate disease severity $[4,6,7]$. Research can provide evidence that miRNA can be used as diagnostic and prognostic biomarkers and help in the classification of patients as well as in defining disease advancement and predict future outcome $[6,7]$. Among many miRNAs, miR-146, miR-155, miR143 , and miR-145 emerged as key regulators of the immune system $[8,9]$. MiR-146a is a negative feedback regulator of the innate and adaptive immune response. It regulates TLR signaling pathway and IFN type1 production. It also participates in the proper functioning of Treg cells and Th17-induced differentiation [8, 10-15]. MiR-155 facilitates cellular proinflammatory response. It is necessary for the proper immune cell activation and production of proinflammatory cytokines; its presence promotes cell survival, growth, migration, and antipathogenic response $[8,9,15-19]$. miR-143/miR-145 play an important role in intestinal physiology and cancer formation. It enhances proliferation, migration, and invasion of cancer cells [20-28]. Due to the great importance of these microRNAs in the functioning of the immune system and the relationship of these microRNAs with the occurrence of other ACTDs, assessing whether they are also associated with MCTD patients seems justified.

The aim of this work was an evaluation of the possible involvement of key to immune system miRNAs in MCTD. We performed genotype/haplotype association analysis to assess whether selected miRNA SNPs are associated with the incidence and clinical picture of MCTD. Moreover, we evaluated differences in serum miRNA expression in MCTD patients compared to healthy controls. We also analyzed if selected genotypes are connected with the serum concentration of proinflammatory cytokines in patients suffering from MCTD. To our knowledge, this is the first study concerning the epigenetic association with MCTD.

\section{Patient data materials and methods Study population}

A total of 169 patients suffering from MCTD (84\% of women and $16 \%$ of men with mean age $43.43 \pm 13.77$ ) diagnosed at the Clinic and Polyclinic of Connective Tissue Diseases of the National Institute of Geriatrics, Rheumatology and Rehabilitation in Warsaw and 575 healthy people $(61.92 \%$ of women and $58.08 \%$ of men with mean age $37.29 \pm 12.08$ ) from Warsaw Center for Blood Donation were recruited to the case-control study (Caucasian origin). Patients met the diagnostic criteria of Kasukawa and/or Alarcon-Segovia and Villarreal. Healthy subjects did not have a history of autoimmune and/or inflammatory disease at the time of sampling. Autoantibodies to dsDNA, Scl-70, Sm, Ro, La, RibP, His, PCNA, CENPB, and Jo-1 were determined in the serum using DOT-blot tests (recomLine ANA/ENA, Mikrogen Diagnostik, Neuried, Germany). The identification of anti-U1-RNP was performed by electrochemiluminescence (ECLIA) using streptavidin-coated paramagnetic beads (UNICAP100, Phadia, Sweden). The presence of antinuclear antibodies (ANA) was determined by indirect immunofluorescence (IF) on Hep2 cell lines (Euroimmun Polska, Wroclaw, Poland), with a median titer of 1:5840 (range 1:80-1:40,960).

All participants signed informed written consent for participation in the study. The study was approved by the ethics committee in the National Institute of Geriatrics Rheumatology and Rehabilitation, Warsaw, Poland. 


\section{Genotyping}

Genomic DNA extraction was performed from peripheral blood using either the salting-out procedure or DNA isolation kit (Qiagen). Allelic discrimination of miR-155 rs1893650, rs2829806, miR-143 rs353299, rs353291, rs713147, rs353298, and miR-146a rs2910164 (Supplementary Table 1) was performed using TaqMan ${ }^{\circ}$ probes (Applied Biosystems, Carlsbad, CA, USA) on the QuantStudio 5 Real-Time PCR System (ThermoFisher Scientific, USA). The reaction was performed in a total volume of $10 \mu \mathrm{l}$, and reaction conditions were as follows: denaturation at $95^{\circ} \mathrm{C}$ for $10 \mathrm{~min}$, followed by 40 cycles of denaturation at $92^{\circ} \mathrm{C}$ for $15 \mathrm{~s}$, and annealing and extension at $60^{\circ} \mathrm{C}$ for $1 \mathrm{~min}$. The first step of SNP selection for the analysis was based on the 1000 genome EUR, ExAC Europe, or HapMap CEU Data base. We choose only this SNP, which minor allele frequency was greater than 0.02 . The second stage was based on the literature; we decided to choose SNP examined earlier in the context of connective tissue diseases.

\section{Assay for serum levels of TNF- $a$, IL-6, and IFN- $\gamma$}

TNF- $\alpha$, IL- 6 , and IFN- $\gamma$ protein concentrations, in the serum of 100 randomly selected MCTD patients and 130 healthy subjects, were determined using ELISA DRG diagnostics immunosorbent assays (REF: EIA-4641, REF: EIA-4640, and REF: EIA-4434 respectively) (DRG International, Inc. USA), following the manufacturer's instructions. Plates were read on a microplate reader (El $\times$ 800, BIO-TEK Winooski, United States Instruments).

\section{miRNA relative expression}

The expression level of miRNAs in the serum was determined using qRT-PCR in 22 MCTD patients and 38 healthy controls. miRNA from 200- $\mu$ l freshly isolated serum was extracted using AA Biotech MicroRNA Concentrator (A\&A Biotechnology, Poland) according to the manufacturer's protocol. Multiplexed reverse transcription and preamplification reactions were performed according to the Protocol for Creating Custom RT and Preamplification (Publication Part Number 4465407 Revision Date January 2013 (Rev. C), Applied Biosystems by Life Technologies); Taqman miRNA assays (miR-143 TM:002249, miR-145 TM:002278, miR-155 TM:002623, U6 - TM:001973) were used to determine the expression of selected miRNAs following the manufacturer's instructions. Each target was measured in triplicate and normalized to the level of U6.

\section{IRAK1 and TRAF6 mRNA relative expression}

Total RNA was isolated from whole blood using AA Biotech MicroRNA Concentrator (A\&A Biotechnology, Poland). cDNA was obtained using the High Capacity cDNA Reverse Transcription Kit with RNase Inhibitor
(Applied Biosystems, Foster City, CA). qPCR was performed in 45 MCTD patients and 49 healthy controls using TaqMan Gene Expression Assays (IRAK1 HS00155570_m1 and TRAF6 - Hs00377558_m1) (Applied Biosystems, Foster City, CA) according to manufacturer's instructions. Each target was measured in triplicate and normalized to the level of GAPDH.

\section{Statistical analysis}

The results were presented as a median and interquartile range (IQR) for non-normally distributed continuous variables or mean with one standard deviation for normally distributed continuous variables. The consistency of genotype distribution with Hardy-Weinberg equilibrium (HWE) was performed using the HWE exact test with "genetics" R package (Gregory Warnes, with contributions from Gregor Gorjanc, Friedrich Leisch and Michael Man (2019) genetics: Population Genetics. R package version 1.3.8.1.1. https://CRAN.Rproject.org/package). Genotype and allele distribution between groups was evaluated using logistic regression (OR, 95\% confidence intervals, $p$ value). The analysis considered the effect of possible confounders like age and gender. The analysis was calculated under dominant, codominant, overdominant and recessive, and allelic models. The presence of LD for haplotypes and LD heatmap were determined using package "genetics" and "LDheatmap" R packages. Differences between tested SNPs, disease activity parameters, and cytokine serum concentrations were analyzed using the Kruskal-Wallis test, Mann-Whitney test, or analysis of variance for continuous variables and $\chi^{2}$ or Fisher exact test for categorical variables. A $p$ value $<0.05$ indicated a statistically significant result. Only for haplotypes Bonferroni correction was used to adjust the significance of $p$ value for multiple testing. The relative expression level of miRNAs was computed using the $2-\Delta \Delta \mathrm{Ct}$ method (Livak) with normalization to the endogenous small RNA control, U6. Effect size for the Kruskal-Wallis test was presented by $\varepsilon$ square [29]. The statistical analysis and figure preparation were carried out using the R program (HTTP: //www.R-project.org.) supplemented with the following packages: Gregory Warnes, with contributions from Gregor Gorjanc, Friedrich Leisch, and Michael Man (2019). genetics: Population Genetics. R package version 1.3.8.1.1. https://CRAN.R-project.org/package=genetics; Juan R González, Lluís Armengol, Elisabet Guinó, Xavier Solé, and Víctor Moreno (2014). SNPassoc: SNPs-based whole genome association studies. $\mathrm{R}$ package version 1.9-2. https://CRAN.R-project.org/package=SNPassoc; H. Wickham. ggplot2: Elegant Graphics for Data Analysis. Springer-Verlag New York, 2016. Ogle, D.H., P. Wheeler, and A. Dinno. 2018. FSA: Fisheries Stock Analysis. $\mathrm{R}$ package version 0.8.22, https:/github.com/ 
droglenc/FSA; Sinnwell JP and Schaid DJ (2018). haplo.stats: Statistical Analysis of Haplotypes with Traits and Covariates when Linkage Phase is Ambiguous. $R$ package version 1.7.9. https://CRAN.R-project.org/package= haplo.stats

\section{Results}

\section{MCTD patients' clinical characteristics}

The demographic and clinical characteristics of our MCTD patients are presented in Table 1. MCTD patients who met the classification criteria for two different CTDs at the blood sampling were excluded from the study. The most common symptoms of the MCTD activity were as follows: swelling fingers or hands $(92 \%$ of MCTD patients), decreased number of leukocytes and/or platelets, increased ESR and/or CRP levels, hypergammaglobulinemia, and skin rashes. Damage most commonly affected the skin, musculoskeletal and cardiovascular systems, and lungs. The clinical picture of MCTD is very variable. Almost all MCTD patients presented with Raynaud's phenomenon (97\% of MCTD patients) right at the onset of the disease. Pulmonary arterial hypertension $(\mathrm{PAH})$, routinely screened in MCTD patients, was detected in $31 \%$ of our patients. Antinuclear antibodies (ANA) in titer $>1: 320$ were detected in 99\% of patients with MCTD. All our MCTD patients had anti-U1-RNP antibodies, where anti-70K was detected in $75 \%$ of patients, anti-A in $83 \%$ of patients, and anti-C in $79 \%$ of patients. Patients' therapeutic profile presented as follows: immunosuppressive drugs (azathioprine $6 \%$ ), methotrexate (23\%), corticosteroids (prednisone $77 \%$ ), and antimalarics (chloroquine 59\%).

\section{miRNA genotype distribution between MCTD patients and healthy subjects}

We performed genotype distribution analysis, for two miR-155 SNPs (rs1893650 and rs2829806), four miR-143 SNPs (rs353291, rs353298, rs353299, rs713147), and one miR-146a (rs2910164), between MCTD and healthy controls. All examined SNPs were consistent with the Hardy-Weinberg equilibrium (HWE) $(p>0.05$, Supplementary Table 1). The minor allele frequency (MAF) of all examined SNPs in our subjects, MCTD patients, and healthy controls were similar to those in the Utah Residents $(\mathrm{CEPH})$ with Northern and Western Ancestry and in the European ancestry.

miRNA genetic variant distribution was calculated under dominant, codominant, overdominant, recessive, and allelic models (Table 2). We observed only a tendency where miR-146a rs2910164 G allele and GG genotype were more frequent in healthy subjects than in MCTD patients ( $81 \%$ vs $75 \%$ and $65 \%$ vs $56 \%$, respectively). Nevertheless, differences observed in miR-146a rs2910164 codominant (GG vs GC vs CC) $(p=0.07)$ and overdominant ( $\mathrm{GC}$ vs $\mathrm{CC}+\mathrm{GG})(p=0.09)$ models were not statistically significant. We also observed that miR143 rs713147 A allele has shown a tendency to more frequent occurrence in healthy subjects than in MCTD patients, thus conferring disease protection nature to this allele. Distribution of other examined SNPs did not show statistically significant differences between studied groups.

\section{Haplotype association with the risk of MCTD}

In the next step, we investigated the genetic association between miRNA haplotypes and MCTD. To create the haplotypes, miR-143 SNPs were analyzed in the following sequence: rs353299, rs353291, rs713147, and rs353298. Haplotypes with frequency $<0.03$, in both examined groups, were ignored. We observed that two miR-143 haplotypes TTTG and CCTA occur much more frequently in MCTD patients than in healthy people ( $31 \%$ vs $14 \%, p<0.001$ and $23 \%$ vs $11 \%, p=0.002$ respectively) (Table 3 ). In contrast, the miR-143 haplotypes CTTG, TTAA, TCTA, and TTTA occur much more frequently in healthy subjects than in MCTD patients $(7 \%$ vs $1 \%, 4 \%$ vs $0 \%, 6 \%$ vs $1 \%$, and $5 \%$ vs $1 \%$, respectively). Haplotype analysis of miRNA-155 did not show differences between study groups (data not shown). The strongest LD was observed between miR143 rs353298 and rs353299 $D^{\prime}=0.7, r^{2}=0.5$; LD between other miR143 variants was low (Supplementary Figure 1).

\section{Association of the miR-155, miR-143, and miR-146a genetic variants with the clinical features of MCTD patients}

We evaluated an association between the miR-155, miR146a, and miR-143 genotypes and haplotypes and the occurrence of individual clinical symptoms of MCTD. Analysis was performed on 100 MCTD patients with detailed clinical description. Our analysis indicated that miR-146a and miR-143 gene polymorphisms are associated with some clinical parameters indicating a more severe course of the disease.

miR-146a rs2910164 CC genotype and C allele were associated with scleroderma (Table 4$)$. Recessive $(p=$ $0.01, \mathrm{OR}=18.74)$, codominant $(p=0.04, \mathrm{OR}=22.94)$, and allelic $(p=0.02, \mathrm{OR}=2.17)$ models showed that among miR-146a rs2910164 CC carriers, scleroderma was much more common. In contrary, miR-146a rs2910164 CC and GC genotypes and C allele occurred less frequent among MCTD patients with lymphadenopathy. It has to be noted that among the patients for whom we had information on, only 4 people have the CC genotype. 
Table 1 Clinical characteristics of patients with MCTD

MCTD

Clinical parameters

Demographic characteristics

Autoantibody profile

\begin{tabular}{|c|c|}
\hline & Anti-U1 RNP \\
\hline & Anti-CCP \\
\hline & Anti-ANA \\
\hline & Anti-SmB \\
\hline & Anti-SmD \\
\hline & Anti-Ro 60 \\
\hline & Anti-Ro 52 \\
\hline & Anti-La \\
\hline & Anti-Rib P \\
\hline & Anti-PCNA \\
\hline & Anti-CENP B \\
\hline & Anti-Scl-70 \\
\hline & Anti-Jo-1 \\
\hline & Anti-His \\
\hline & Anti-DNA \\
\hline & RF \\
\hline Clinical manifestation & SLE-like skin lesions \\
\hline & Ocular lesions \\
\hline & Cardiomyopathy \\
\hline & Dysphagia \\
\hline & Deforming or erosive arthritis \\
\hline & Poikiloderma \\
\hline & Raynaud syndrome \\
\hline & Sjögren's syndrome \\
\hline & Swollen fingers or hands \\
\hline & Polyarthritis \\
\hline & Lymphadenopathy \\
\hline & Facial erythema \\
\hline & Pericarditis/pleuritis \\
\hline & Leukopenia/thrombocytopenia \\
\hline & Scleroderma \\
\hline
\end{tabular}

Age

Disease duration [months]

Damage index

The course of disease
Mean values \pm SD or $n^{* *}(\%)$

$N^{*}$

$43.43 \pm 13.77471$

$84(84 \%)$

100

$148.2 \pm 272.6612$

Single phase

$9.79 \pm 13.547$

Multiphase

$12(12 \%)$

$28(28 \%)$

Progressive

$60(60 \%)$

100

99 (99\%)

70

75 (75\%)

A

C

100

$83(83 \%)$

79 (79\%)

100

3 (4.22\%)

99

98 (98.98\%)

100

31 (31\%)

6 (6\%)

$10(10 \%)$

$24(24 \%)$

2 (2\%)

3 (3\%)

1 (1\%)

0

2 (2\%)

1 (1\%)

$15(15 \%)$

$13(13 \%)$

36 (36.73\%)

$71(71 \%)$

$60(60.60 \%)$

$4(4 \%)$

$22(22 \%)$

12 (13\%)

31 (31\%)

97 (97\%)

22 (31.88\%)

92 (92\%)

94 (94\%)

26 (26\%)

43 (43\%)

$16(16 \%)$

65 (65\%)

34 (34\%) 
Table 1 Clinical characteristics of patients with MCTD (Continued) MCTD

\begin{tabular}{llll}
\hline Clinical parameters & & $\boldsymbol{N}^{*}$ & Mean values \pm SD or $\boldsymbol{n}^{* *}(\%)$ \\
\hline & Pulmonary fibrosis & 100 & $31(31 \%)$ \\
& Esophageal disorders & 100 & $23(23 \%)$ \\
& Myopathy & 100 & $66(66 \%)$ \\
\hline
\end{tabular}

$R F$ rheumatoid factor, CCP anti-CCP antibodies, U1 RNP anti-U1RNP antibodies, ANA antinuclear antibodies, 70 anti-U1 $70 \mathrm{kDa}$ antibodies, $A$ anti-U1 A antibodies, $C$ anti-U1 C antibodies, SmB anti-Sjögren's syndrome type B antibodies, SmD anti-SmD antibody, Ro 60 anti-Ro-60 antibody, Ro 52 anti-Ro52 antibody, La antibody to the La antigen, Rib P anti-ribosomal P protein antibody, PCNA anti-PCNA antibody, CENP B anti-CENP-B antibody, SCl-70 anti-SCl-70 antibodies, Jo-1 anti-Jo-1 antibody, His anti-histone antibody, DNA anti-dsDNA antibody

${ }^{*} N$, number of patients with clinical information

${ }^{* *} n$, number of patients with positive clinical manifestation

Association analysis of miR-143 rs353299 C/T polymorphism showed that among MCTD patients with miR-143 rs353299 CT genotype, swollen fingers or hands, the presence of enlarged lymph nodes, and pericarditis/pleuritic were observed more often compare to MCTD patients with other miR-143 rs353299 genotypes (Table 5). On the other hand, the miR-143 rs353299 TT genotype appears to be protective, although differences were not significant. Within MCTD patients carrying miR-143 rs353299 TT genotype, swollen fingers or hands $(p=0.07$ recessive model) and lymphadenopathy $(p=0.06$ recessive model) were observed less than in MCTD patients with other miR-143 rs353299 genotypes.

Our analysis showed that miR-143 rs353298 A/G genetic variant was associated with the occurrence of pericarditis/pleuritis and scleroderma (Table 6). The miR-143 rs353298 GG genotype occurrence was associated with pericarditis/pleuritis symptom. The results indicated that MCTD patients who were GG homozygotes much more often suffered from pericarditis/pleuritis than in the MCTD patient with other genotypes (35\% vs $12 \%, p=0.04$ recessive model, $p=0.04$ codominant model). On the other hand, MCTD patients with miR143 rs353298 GG genotype were less likely to experience scleroderma than MCTD patients with other genotypes (recessive model $p=0.05$ ).

The miR-143 rs353291 T/C gene polymorphism showed association only with pericarditis/pleuritis (Table 7). We observed that this symptom occurs less frequent in MCTD patients with miR-143 rs353291 TC genotype ( $p=0.03$ overdominant model).

\section{Impact of miRNA polymorphisms on inflammatory cytokine levels in serum}

miRNAs, which are critical in the development of the immune response, are involved in controlling genes associated with cytokine secretion and regulation of the cytokine serum levels. Therefore, we decided to check if examined miRNA polymorphisms may have an impact on the levels of the inflammatory cytokine levels in serum in our study groups. IL-6, TNF- $\alpha$, and IFN- $\gamma$ levels in serum were assessed in both MCTD patients and healthy subjects.

First, we compared TNF- $\alpha$, IFN- $\gamma$, and IL- 6 levels in serum between MCTD patients and healthy subjects (data not shown). We found that serum TNF- $\alpha$, IFN- $\gamma$, and IL-6 levels were significantly higher in MCTD patients compared to healthy subjects ( $p<0.001$ in each case).

Second, we performed an analysis of the association between miR-155, miR-146a, and miR-143 genotypes and serum TNF- $\alpha$, IFN- $\gamma$, and IL- 6 levels in MCTD patients and control groups. Our results demonstrated a significant interaction between TNF- $\alpha$, IFN- $\gamma$, and miR143 genetic variants. Serum levels of IFN- $\gamma$ were significantly higher within healthy subjects carrying miR-143 rs713147 TT genotype ( $p=0.05, \varepsilon^{2}=0.09$, Fig. 1$)$. However, in the group of MCTD patients, we did not observe any differences in serum levels of IFN- $\gamma$ between miR143 rs713147 genotypes ( $p=0.6, \varepsilon^{2}=0.01$, Fig. 1 ). Analysis of TNF- $\alpha$ showed that miR-143 rs353299 CT and miR-143 rs353298 AG genotypes in healthy subjects were associated with higher TNF- $\alpha$ levels in serum $(p=$ $0.03, \varepsilon^{2}=0.06 ; p=0.03, \varepsilon^{2}=0.06$; respectively, Fig. 2 ). In the MCTD patients, the TNF- $\alpha$ serum levels were generally higher, but we did not observe differences between individual miR-143 rs353299 and miR-143 rs353298 genotypes $\left(p=0.57, \varepsilon^{2}=0.02 ; p=0.36, \varepsilon^{2}=\right.$ 0.04; respectively). In case of IL-6, we found no significant correlation between miRNA genotypes and IL-6 serum levels among both study groups, MCTD patients and healthy subjects.

\section{Association between miR-146a SNP distribution and TRAF6 and IRAK1 mRNA expression in whole blood}

Distribution analysis indicated that only miR-146a may be associated with an increased risk of developing MCTD in our population. As we have known, miR-146a regulates immune and inflammatory signaling through TRAF-6/IRAK-1 pathway [30]. Based on these reports, we wondered whether miRNA-146a polymorphisms may affect the level of TRAF6 and IRAK1 gene expression. In the present study, the mRNA expression of the TRAF6 and IRAK1 were examined in the whole blood of 45 
Table 2 Distribution of genotypes and allele frequencies of miRNA SNPs among patients with MCTD and healthy subjects $(p=$ MCTD vs controls)

\begin{tabular}{|c|c|c|c|c|c|}
\hline SNP & Genotype & $\begin{array}{l}\text { MCTD } \\
n(\%)\end{array}$ & $\begin{array}{l}\text { Controls } \\
n(\%)\end{array}$ & $\begin{array}{l}\text { Adjusted OR } \\
(95 \% \mathrm{Cl})\end{array}$ & $p$ value \\
\hline \multicolumn{6}{|c|}{ miR-155 rs1893650 C/T } \\
\hline \multirow[t]{3}{*}{ Codominant } & CC & $79(56.43)$ & $333(62.95)$ & - & - \\
\hline & $C T$ & $57(40.71)$ & $173(32.70)$ & $1.42(0.89-2.27)$ & 0.1 \\
\hline & $\pi$ & $4(2.86)$ & $23(4.35)$ & $0.82(0.19-2.62)$ & 0.8 \\
\hline \multirow[t]{2}{*}{ Dominant } & CC & $79(56.43)$ & $333(62.95)$ & - & - \\
\hline & $\pi+C T$ & $61(43.57)$ & $196(37.05)$ & $1.35(0.86-2.13)$ & 0.2 \\
\hline \multirow[t]{2}{*}{ Recessive } & $\mathrm{CC}+\mathrm{CT}$ & $136(97.14)$ & $506(95.65)$ & - & - \\
\hline & $\pi$ & $4(2.86)$ & $23(4.35)$ & $0.73(0.16-2.25)$ & 0.6 \\
\hline \multirow[t]{2}{*}{ Overdominant } & $\pi+C C$ & $83(59.29)$ & $356(67.30)$ & - & - \\
\hline & $C T$ & $57(40.71)$ & $173(32.70)$ & $1.44(0.90-2.27)$ & 0.1 \\
\hline \multirow[t]{2}{*}{ Alleles } & C & 215 (76.79) & $839(79.3)$ & - & - \\
\hline & $\mathrm{T}$ & $65(23.21)$ & $219(20.7)$ & $1.16(1.59-0.85)$ & 0.36 \\
\hline \multicolumn{6}{|c|}{ miR-155 rs2829806 G/T } \\
\hline \multirow[t]{3}{*}{ Codominant } & GG & $71(59.66)$ & $285(61.69)$ & & - \\
\hline & GT & $44(36.9)$ & $153(33.12)$ & $1.29(0.77-2.13)$ & 0.3 \\
\hline & $\pi$ & $4(3.3)$ & $24(5.19)$ & $0.63(0.13-2.12)$ & 0.5 \\
\hline \multirow[t]{2}{*}{ Dominant } & GG & $71(59.6)$ & 285 (61.69) & - & - \\
\hline & $T+\mathrm{GT}$ & $48(40.4)$ & $177(38.31)$ & $1.2(0.73-1.95)$ & 0.4 \\
\hline \multirow[t]{2}{*}{ Recessive } & $\mathrm{CC}+\mathrm{GT}$ & 115 (96.6) & $438(94.8)$ & - & - \\
\hline & $\pi$ & $4(3.36)$ & $24(5.19)$ & $0.58(0.12-1.89)$ & 0.4 \\
\hline \multirow[t]{2}{*}{ Overdominant } & $T T+G G$ & $75(63.03)$ & 309 (66.88) & - & - \\
\hline & GT & $44(36.97)$ & $153(33.12)$ & $1.33(0.80-2.17)$ & 0.2 \\
\hline \multirow[t]{2}{*}{ Alleles } & $\mathrm{T}$ & $52(21.85)$ & $201(21.75)$ & - & - \\
\hline & G & $186(78.15)$ & $723(78.25)$ & $1(1.42-0.71)$ & 0.9 \\
\hline \multicolumn{6}{|c|}{ miR-146a rs29101164 G/C } \\
\hline \multirow[t]{3}{*}{ Codominant } & GG & $69(55.65)$ & 316 (64.89) & - & - \\
\hline & GC & $51(41.12)$ & $153(31.42)$ & $1.47(0.74-8.68)$ & 0.1 \\
\hline & $\mathrm{CC}$ & $4(3.23)$ & $18(3.7)$ & $2.80(0.89-2.41)$ & 0.09 \\
\hline \multirow[t]{2}{*}{ Dominant } & GG & $69(55.65)$ & 316 (64.89) & - & - \\
\hline & $C C+G C$ & $55(44.35)$ & $171(35.11)$ & $1.55(0.96-2.51)$ & 0.07 \\
\hline \multirow[t]{2}{*}{ Recessive } & $\mathrm{GG}+\mathrm{GC}$ & $120(96.77)$ & $469(96.30)$ & - & - \\
\hline & CC & $4(3.23)$ & $18(3.7)$ & $2.43(0.65-7.36)$ & 0.1 \\
\hline \multirow[t]{2}{*}{ Overdominant } & $\mathrm{CC}+\mathrm{GG}$ & $73(58.87)$ & $334(68.58)$ & - & - \\
\hline & GC & $51(41.12)$ & $153(31.42)$ & $1.40(0.85-2.26)$ & 0.2 \\
\hline \multirow[t]{2}{*}{ Alleles } & C & $59(24.58)$ & $189(19.40)$ & - & - \\
\hline & G & $181(75.42)$ & $785(80.60)$ & $1.35(1.89-0.97)$ & 0.08 \\
\hline \multicolumn{6}{|c|}{ miR-143 rs353291 T/C } \\
\hline \multirow[t]{3}{*}{ Codominant } & $\Pi T$ & $47(39.50)$ & $140(36.46)$ & - & - \\
\hline & $\mathrm{TC}$ & $51(42.86)$ & $184(47.92)$ & $0.95(0.55-1.66)$ & 0.8 \\
\hline & CC & $21(17.65)$ & $60(15.63)$ & $1.17(0.57-2.35)$ & 0.6 \\
\hline \multirow[t]{2}{*}{ Dominant } & $\pi$ & $47(39.50)$ & $140(36.46)$ & - & - \\
\hline & $\mathrm{CC}+\mathrm{CT}$ & $72(60.5)$ & $244(63.54)$ & $1.01(0.60-1.70)$ & 0.9 \\
\hline Recessive & $T+C T$ & $98(82.35)$ & $324(84.37)$ & - & - \\
\hline
\end{tabular}


Table 2 Distribution of genotypes and allele frequencies of miRNA SNPs among patients with MCTD and healthy subjects ( $p=$ MCTD vs controls) (Continued)

\begin{tabular}{|c|c|c|c|c|c|}
\hline SNP & Genotype & $\begin{array}{l}\text { MCTD } \\
n(\%)\end{array}$ & $\begin{array}{l}\text { Controls } \\
n(\%)\end{array}$ & $\begin{array}{l}\text { Adjusted OR } \\
(95 \% \mathrm{Cl})\end{array}$ & $p$ value \\
\hline & CC & $21(17.65)$ & $60(15.63)$ & $1.2(0.62-2.24)$ & 0.5 \\
\hline \multirow[t]{2}{*}{ Overdominant } & $\mathrm{TT}+\mathrm{CC}$ & $68(57.14)$ & $200(52.08)$ & - & - \\
\hline & $\mathrm{TC}$ & $51(42.86)$ & $184(47.92)$ & $0.91(0.55-1.48)$ & 0.7 \\
\hline \multirow[t]{2}{*}{ Alleles } & $\mathrm{T}$ & $145(60.92)$ & $464(60.42)$ & - & - \\
\hline & C & 93 (39.08) & 304 (39.58) & $0.97(1.32-0.73)$ & 0.9 \\
\hline \multicolumn{6}{|c|}{ miR-143 rs713147 T/A } \\
\hline \multirow[t]{3}{*}{ Codominant } & $\pi$ & $63(54.31)$ & $148(44.31)$ & - & - \\
\hline & TA & $44(37.93)$ & $148(44.31)$ & $0.72(0.41-1.23)$ & 0.2 \\
\hline & AA & $9(7.76)$ & $38(11.38)$ & $0.52(0.19-1.27)$ & 0.1 \\
\hline \multirow[t]{2}{*}{ Dominant } & $\pi$ & $63(54.31)$ & $148(44.31)$ & - & - \\
\hline & $\mathrm{AA}+\mathrm{TA}$ & $53(45.69)$ & $186(55.69)$ & $0.68(0.40-1.12)$ & 0.1 \\
\hline \multirow[t]{2}{*}{ Recessive } & $\mathrm{TT}+\mathrm{TA}$ & $107(92.24)$ & $276(88.62)$ & - & - \\
\hline & AA & $9(7.76)$ & $38(11.38)$ & $0.61(0.23-1.42)$ & 0.2 \\
\hline \multirow[t]{2}{*}{ Overdominant } & $\Pi+A A$ & $72(62.07)$ & $186(55.69)$ & - & - \\
\hline & TA & $44(37.93)$ & $148(44.31)$ & $0.80(0.47-1.34)$ & 0.4 \\
\hline \multirow[t]{2}{*}{ Alleles } & $\mathrm{T}$ & $170(73.28)$ & $444(66.47)$ & - & - \\
\hline & A & $62(26.72)$ & $224(33.53)$ & $0.72(1-0.52)$ & 0.06 \\
\hline \multicolumn{6}{|c|}{ miR-143 rs353298 A/G } \\
\hline \multirow[t]{3}{*}{ Codominant } & AA & $47(39.17)$ & $179(37.61)$ & - & - \\
\hline & $A G$ & $53(44.17)$ & $233(48.95)$ & $0.95(0.56-1.61)$ & 0.8 \\
\hline & GG & $20(16.17)$ & $64(13.45)$ & $1.32(0.64-2.62)$ & 0.4 \\
\hline \multirow[t]{2}{*}{ Dominant } & AA & $47(39.17)$ & $179(37.61)$ & - & - \\
\hline & $\mathrm{GG}+\mathrm{AG}$ & $73(60.83)$ & $297(62.39)$ & $1.03(0.63-1.70)$ & 0.8 \\
\hline \multirow[t]{2}{*}{ Recessive } & $\mathrm{AA}+\mathrm{AG}$ & $100(83.33)$ & $412(86.55)$ & - & - \\
\hline & GG & $20(16.17)$ & $64(13.45)$ & $1.36(0.70-2.51)$ & 0.3 \\
\hline \multirow[t]{2}{*}{ Overdominant } & $\mathrm{AA}+\mathrm{GG}$ & $67(55.83)$ & $243(51.05)$ & - & - \\
\hline & $A G$ & $53(44.17)$ & $233(48.95)$ & $0.87(0.53-1.40)$ & 0.5 \\
\hline \multirow[t]{2}{*}{ Alleles } & A & $147(61.25)$ & $591(62.08)$ & - & - \\
\hline & G & $93(38.75)$ & 361 (37.92) & $1.04(1.39-0.77)$ & 0.81 \\
\hline \multicolumn{6}{|c|}{ miR-143 rs353299 C/T } \\
\hline \multirow[t]{3}{*}{ Codominant } & $\mathrm{CC}$ & $47(38.52)$ & $130(38.92)$ & - & - \\
\hline & $\mathrm{TC}$ & $56(45.90)$ & $162(48.50)$ & $1.13(0.64-1.98)$ & 0.6 \\
\hline & $\pi$ & $19(15.57)$ & $42(12.57)$ & $1.35(0.61-2.93)$ & 0.4 \\
\hline \multirow[t]{2}{*}{ Dominant } & CC & 47 (38.52) & $130(38.92)$ & - & - \\
\hline & $\mathrm{TT}+\mathrm{CT}$ & 75 (38.52) & $204(38.92)$ & $1.18(0.69-2.01)$ & 0.5 \\
\hline \multirow[t]{2}{*}{ Recessive } & $\mathrm{CC}+\mathrm{CT}$ & 103 (84.43) & $292(87.43)$ & - & - \\
\hline & $\pi$ & $19(15.57)$ & $42(12.57)$ & $1.27(0.60-2.54)$ & 0.5 \\
\hline \multirow[t]{2}{*}{ Overdominant } & $\mathrm{TT}+\mathrm{CC}$ & $66(54.1)$ & $172(51.5)$ & - & - \\
\hline & $\mathrm{TC}$ & $56(45.90)$ & $162(48.50)$ & $1.04(0.62-1.72)$ & 0.8 \\
\hline \multirow[t]{2}{*}{ Alleles } & $C$ & $150(61.48)$ & $422(63.17)$ & - & - \\
\hline & $\mathrm{T}$ & $94(38.52)$ & $246(36.83)$ & $1.08(1.45-0.79)$ & 0.64 \\
\hline
\end{tabular}


Table 3 miR-143 haplotype distribution

\begin{tabular}{|c|c|c|c|c|c|c|}
\hline rs353299 & rs353291 & rs713147 & rs353298 & $p$ value & $\begin{array}{l}\text { Hap-Freq } \\
\text { Healthy control }\end{array}$ & Hap-Freq MCTD \\
\hline$T$ & $\mathrm{~T}$ & $T$ & G & $<0.0001$ & 0.14 & 0.31 \\
\hline C & C & T & $A$ & 0.002 & 0.11 & 0.23 \\
\hline C & $\mathrm{T}$ & T & G & 0.004 & 0.07 & 0.01 \\
\hline $\mathbf{T}$ & $\mathrm{T}$ & A & $A$ & 0.008 & 0.04 & NA \\
\hline$T$ & C & T & $A$ & 0.009 & 0.06 & 0.01 \\
\hline $\mathbf{T}$ & $\mathrm{T}$ & T & $A$ & 0.02 & 0.05 & 0.01 \\
\hline C & C & $\mathrm{T}$ & G & 0.16 & 0.04 & 0.02 \\
\hline
\end{tabular}

MCTD mixed connective tissue diseases, Hap-Freq haplotype frequency; $2 n_{M C T D}-2102 \mathrm{n}_{\text {Control }}-470$ Bonferroni correction was used to adjust the significance of $p$ value. $p$ value $<0.003$ was considered as significant

MCTD patients and 49 healthy subjects. We observed that mRNA expression of IRAK1 as well as TRAF6 were higher in the MCTD patients compared to controls, but only in the case of TRAF6, this difference was statistically significant (Supplementary Figure 2). In our study, we did not find an association between miR-146a SNPs and TRAF6/IRAK1 mRNA expression in both examined groups.

\section{miRNA expression in the sera of MCTD patients and healthy subjects}

To evaluate the serum miR-143, miR-155, and miR-146a expression, we performed the analysis of the miRNA expression in 21 MCTD patients and 36 controls. We observed that serum miR-143, miR-155, and miR-146a expression were higher in MCTD patients compared to healthy subjects; however, these differences were not significant (Supplementary Figure 3).

\section{Discussion}

The pathogenesis of autoimmune diseases is very complex, and many factors contribute to the abnormal functioning of the immune system.

Despite the growing knowledge of the importance of epigenetics in the regulation of immune response and the development of autoimmune diseases, there is still little research which relates to overlapping syndromes such as MCTD. Our research is the first study that examined the miRNA gene polymorphisms as well as expression in patients with MCTD. We investigated the association between the key in immune-regulation miRNAs: miR-155, miR-143, and miR-146a and MCTD.

Distribution analysis revealed that out of all microRNAs studied only miR-146a rs2910164 C allele may result in a genetic predisposition to MCTD. We observed a slight tendency where "CC + GC" (vs GG) were more characteristic for the MCTD group. These results are in

Table 4 MCTD clinical parameters significantly associated with miR-146a rs2910164 G/C

\begin{tabular}{|c|c|c|c|c|c|c|c|c|}
\hline \multicolumn{9}{|l|}{ Scleroderma } \\
\hline miR-146a rs2910164 G/C & $n(\%)$ & & & Model & $p$ & OR $(95 \% \mathrm{Cl})$ & $95 \% \mathrm{Cl}$ & \\
\hline Genotype & GG & GC & $\mathrm{CC}$ & $\mathrm{CC}+\mathrm{GC}$ vs $\mathrm{GG}$ & 0.14 & $2.06(0.88-4.8)$ & & \\
\hline Scleroderma & $15(27.78)$ & $15(38)$ & $4(100)$ & GG + GC vs CC & 0.01 & 18.74 & 0.9773 & 359.2678 \\
\hline Without scleroderma & $39(72.22)$ & $24(62)$ & $0(0)$ & $C C+G G$ vs $G C$ & 0.72 & 1.28 & 0.55 & 2.99 \\
\hline Allele & G & C & & CC vs GG & 0.04 & 22.94 & 1.1646 & 451.6701 \\
\hline Scleroderma & $45(31)$ & $23(49)$ & & GC vs GG & 0.27 & 1.63 & 0.68 & 3.91 \\
\hline Without scleroderma & $102(69)$ & $24(51)$ & & C vs G & 0.02 & 2.17 & 1.11 & 4.25 \\
\hline \multicolumn{9}{|l|}{ Lymphadenopathy } \\
\hline miR-146a rs2910164 G/C & $n(\%)$ & & & Model & $p$ & OR & $95 \% \mathrm{Cl}$ & \\
\hline Genotype & GG & GC & $\mathrm{CC}$ & $C C+G C$ vs GG & 0.005 & 0.21 & 0.07 & 0.61 \\
\hline Lymphadenopathy & $21(38.89)$ & $5(13)$ & $0(0)$ & $\mathrm{GG}+\mathrm{GC}$ vs CC & 0.57 & 0.283 & 0.0147 & 5.4407 \\
\hline Without lymphadenopathy & $33(61.11)$ & $34(87)$ & $4(100)$ & $\mathrm{CC}+\mathrm{GG}$ vs $\mathrm{GC}$ & 0.01 & 0.26 & 0.09 & 0.76 \\
\hline Allele & $\mathbf{G}$ & $\mathrm{C}$ & & CC vs GG & 0.24 & 0.1731 & 0.0089 & 3.3799 \\
\hline Lymphadenopathy & $47(32)$ & $5(11)$ & & GC vs GG & 0.008 & 0.23 & 0.08 & 0.68 \\
\hline Without lymphadenopathy & $100(68)$ & $42(89)$ & & C vs $\mathbf{G}$ & 0.006 & 0.25 & 0.09 & 0.68 \\
\hline
\end{tabular}

$n$ number of patients with clinical manifestation; $p<0.05$ is considered significant, indicated in bold; $p$ value obtained from $\chi^{2}$ or Fisher exact test 
Table 5 Association between miR-143 rs353299 C/T polymorphism and MCTD clinical parameters

\begin{tabular}{|c|c|c|c|c|c|c|c|c|}
\hline \multicolumn{9}{|l|}{ Swollen fingers or hands } \\
\hline miR-143 rs353299 C/T & $n(\%)$ & & & Model & $p$ & OR & $95 \% \mathrm{Cl}$ & \\
\hline Genotype & $\mathrm{CC}$ & $\mathrm{CT}$ & $\mathrm{TT}$ & $\mathrm{TT}+\mathrm{CT}$ vs CC & 0.25 & 1.87 & 0.36 & 9.83 \\
\hline Swollen fingers or hands & $31(91.18)$ & $46(100)$ & $12(80)$ & $\mathrm{CC}+\mathrm{CT}$ vs TT & 0.07 & 0.16 & 0.03 & 0.86 \\
\hline Without swollen fingers or hands & $3(8.82)$ & $0(0)$ & $3(20)$ & $\mathrm{TT}+\mathrm{CC}$ vs CT & 0.07 & 13.8966 & 0.7600 & 254.09 \\
\hline Allele & $\mathrm{C}$ & $\mathbf{T}$ & & TT vs CC & 0.28 & 0.39 & 0.07 & 2.19 \\
\hline Swollen fingers or hands & $108(95)$ & $70(92)$ & & CT vs CC & 0.12 & 10.33 & 0.5157 & 207.0449 \\
\hline Without swollen fingers or hands & $6(5)$ & $6(8)$ & & C vs T & 0.4679 & 0.65 & 0.2 & 2.09 \\
\hline \multicolumn{9}{|l|}{ Lymphadenopathy } \\
\hline miR-143 rs353299 C/T & $n(\%)$ & & & Model & $p$ & OR & $95 \% \mathrm{Cl}$ & \\
\hline Genotype & $\mathrm{CC}$ & $\mathrm{CT}$ & $\mathrm{TT}$ & $\mathrm{TT}+\mathrm{CT}$ vs CC & 0.35 & 1.81 & 0.67 & 4.87 \\
\hline Lymphadenopathy & $7(20)$ & $18(39)$ & $1(7)$ & $\mathrm{CC}+\mathrm{CT}$ vs TT & 0.06 & 0.16 & 0.02 & 1.28 \\
\hline Without lymphadenopathy & $28(80)$ & $28(61)$ & $14(93)$ & $\mathrm{TT}+\mathrm{CC}$ vs $\mathrm{CT}$ & 0.02 & 3.38 & 1.29 & 8.82 \\
\hline Allele & C & $\mathbf{T}$ & & TT vs CC & 0.26 & 0.29 & 0.03 & 2.56 \\
\hline Lymphadenopathy & $32(28)$ & $20(26)$ & & CT vs CC & 0.07 & 2.57 & 0.93 & 7.12 \\
\hline Without lymphadenopathy & $84(72)$ & $56(74)$ & & C vs T & 0.84 & 0.94 & 0.49 & 1.8 \\
\hline \multicolumn{9}{|l|}{ Pericarditis/pleuritis } \\
\hline miR-143 rs353299 C/T & $n(\%)$ & & & Model & $p$ & OR & $95 \% \mathrm{Cl}$ & \\
\hline Genotype & $\mathrm{CC}$ & $\mathrm{CT}$ & $\mathrm{TT}$ & $\mathrm{TT}+\mathrm{CT}$ vs CC & 0.85 & 20.14 & 6.58 & 61.68 \\
\hline Pericarditis/pleuritis & $5(14.29)$ & $41(89)$ & $6(40)$ & $\mathrm{CC}+\mathrm{CT}$ vs TT & 0.02 & 0.51 & 0.17 & 1.56 \\
\hline Without pericarditis/pleuritis & $30(85.71)$ & $5(11)$ & $9(60)$ & $\mathrm{TT}+\mathrm{CC}$ vs $\mathrm{CT}$ & 0.18 & 29.07 & 9.26 & 91.31 \\
\hline Allele & C & $\mathbf{T}$ & & TT vs CC & 0.05 & 4 & 0.99 & 16.24 \\
\hline Pericarditis/pleuritis & $51(44)$ & $53(70)$ & & CT vs CC & $<0.0001$ & 49.2 & 13.06 & 185.29 \\
\hline Without pericarditis/pleuritis & $65(56)$ & $23(30)$ & & C vs T & 0.0006 & 2.94 & 1.59 & 5.41 \\
\hline
\end{tabular}

$n$ number of patients with clinical information; $p$ value $<0.05$ is considered significant, indicated in bold; $p$ value obtained from $x^{2}$ or Fisher exact test

line with Jazdzewski et al. [31] who showed that the rarer miR-146a rs2910164 C allele (found in the premiR-146a sequence) reduces the amount of pre- and mature 146a. Moreover, a meta-analysis in the Caucasian population showed an increased risk of developing autoimmune diseases in people carrying the miRNA-146a rs2910164 GC and CC genotypes [32]. It is suspected that the miRNA-146a rs2910164 C allele presence contributes to predispositions to AIDs by altering the expression of miR-146a; it is also possible that the miRNA-146a rs2910164 C allele changes the targets of miR-146a-3p. Research using EMSAs and luciferase reporter assays confirmed that the presence of this allele interferes with the binding of nuclear proteins like TRAF6 or IRAK1. A Shao et al. study on sepsis also confirms that the presence of the miRNA-146a rs2910164 CC genotype affects the expression of miR-146a and is associated with increased expression of IRAK1 and TRAF6 [33]. In the present study, TRAF6 and IRAK1 expression analysis does not confirm these observations. It may result from the fact that among our patients, only 4 were carriers of the miRNA-146a rs2910164 CC genotype. Accordingly, to our result, the miRNA-146a rs2910164 CC genotype was significantly more common among MCTD patients with scleroderma. These results emphasize the possible significance of the miRNA-146a rs2910164 CC genotype. Surprisingly, enlarged lymph nodes occurred more frequently in the group of MCTD patients with the miRNA-146a rs2910164 GG genotype (39\% vs $12 \%$ of patients). This result is questionable, considering that the miRNA-146a rs2910164 GG genotype does not affect the expression of mature miR-146a which as a consequence should decrease the inflammatory response. Association studies have indicated that SNPs in miR-146a may affect the susceptibility of autoimmune diseases such as SLE, psoriatic arthritis (PsA), asthma, systemic sclerosis, AS, or telangiectasia. However, there are contradictions. Niu et al. also cite other studies (on the subject of AS, PsA, RA, or SLE) where the significance of the miR-146a SNPs in these diseases was not observed [34]. Although our observation showed a link between miR-146a genetic variant and MCTD onset, data do not allow to draw a clear conclusion and should be replicated. Functional studies are necessary to confirm the direct role of this genotype in the pathogenesis of MCTD. 
Table 6 Association between miR-143 rs353298 A/G polymorphism and MCTD clinical parameters

\begin{tabular}{|c|c|c|c|c|c|c|c|c|}
\hline \multicolumn{9}{|l|}{ Pericarditis/pleuritis } \\
\hline miR-143 rs353298 A/G & $n(\%)$ & & & Model & $p$ & OR & $95 \% \mathrm{Cl}$ & \\
\hline Genotype & AA & AG & GG & $G G+A G$ vs $A A$ & 0.49 & 1.83 & 0.54 & 6.26 \\
\hline Pericarditis/pleuritis & $4(11.11)$ & $5(12)$ & $6(35)$ & $A A+A G$ vs $G G$ & 0.04 & 4.18 & 1.24 & 14.07 \\
\hline Without pericarditis/pleuritis & $32(88.89)$ & $37(88)$ & $11(65)$ & $G G+A A$ vs $A G$ & 0.52 & 0.58 & 0.18 & 1.85 \\
\hline Allele & A & G & & GG vs $A A$ & 0.04 & 4.36 & 1.04 & 18.39 \\
\hline Pericarditis/pleuritis & $13(11)$ & $17(22)$ & & $A G$ vs $A A$ & 0.9129 & 1.08 & 0.27 & 4.37 \\
\hline Without pericarditis/pleuritis & $101(89)$ & $59(78)$ & & G vs $A$ & 0.05 & 2.24 & 1.02 & 4.93 \\
\hline \multicolumn{9}{|l|}{ Scleroderma } \\
\hline miR-143 rs353298 A/G & $n(\%)$ & & & Model & $p$ & OR & $95 \% \mathrm{Cl}$ & \\
\hline Genotype & AA & AG & GG & $G G+A G$ vs $A A$ & 0.87 & 0.84 & 0.35 & 2.01 \\
\hline Scleroderma & $13(36.11)$ & $17(40)$ & $2(12)$ & $A A+A G$ vs $G G$ & 0.05 & 0.21 & 0.05 & 1 \\
\hline Without scleroderma & $23(63.89)$ & $25(60)$ & $15(88)$ & $G G+A A$ vs $A G$ & 0.30 & 1.72 & 0.73 & 4.06 \\
\hline Allele & A & G & & GG vs $A A$ & 0.0814 & 0.24 & 0.05 & 1.2 \\
\hline Scleroderma & $43(38)$ & $21(28)$ & & $A G$ vs $A A$ & 0.6929 & 1.2 & 0.48 & 3.01 \\
\hline Without scleroderma & $71(62)$ & $55(72)$ & & A vs $G$ & 0.1509 & 0.63 & 0.34 & 1.18 \\
\hline
\end{tabular}

$n$ number of patients with clinical information; $p$ value $<0.05$ is considered significant, indicated in bold; $p$ value obtained from $\chi^{2}$ or Fisher exact test

miR-143 is well-known for its tumor-suppressive activity. Its expression prevents chronic inflammation and limits the invasion and migration of tumors [35]. Association analysis between miR-143 genotypes and MCTD incidence did not show any significant differences. However, the analysis of haplotypes showed that two of them, TTTG and CCTA, were more characteristic for the MCTD group (31\% vs $15 \%$ and $23 \%$ vs $11 \%$ respectively). Interestingly, both haplotypes consist of alternative alleles of the tested miR-143 genetic variants (except the rs713147 $\mathrm{T}$ allele, which occurs in both haplotypes). Moreover, our results indicate a relation between single variants of the miR-143 gene and clinical symptoms like swollen fingers or hands, pericarditis/pleuritis, and scleroderma. We have demonstrated associations between examined miR-143 gene polymorphisms and higher serum concentrations of proinflammatory cytokines in the healthy group but not in the MCTD patients. We suspect that even if these miR-143 genetic variants are important, there must be other factors that contribute more significantly to the concentration of these cytokines in serum.

Although the participation of miR-155 in autoimmune disease development has been suggested in many works, our observations do not show that it has a significant role in MCTD susceptibility. There were no associations between clinical symptoms or inflammatory cytokine serum concentration. These observations exclude the miR155 SNPs significant importance in the development of MCTD in the Polish population. The microRNA expression in serum of MCTD patients did not differ significantly from the control group. However, the results were characterized by a large variation within groups, and therefore, we refrain from drawing conclusions based on them.

The limitations of this study include difficult biological materials and patients with different stories and treatment algorithms, which are difficult to diagnose. A small group of patients and the fact that we do not have detailed clinical information for some patients may affect

Table 7 MCTD clinical parameters significantly associated with miR-143 rs353291 T/C

\begin{tabular}{|c|c|c|c|c|c|c|c|c|}
\hline \multicolumn{9}{|l|}{ Pericarditis/pleuritis } \\
\hline \multirow{2}{*}{$\begin{array}{l}\text { miR-143 rs353291 T/C } \\
\text { Genotype }\end{array}$} & \multicolumn{3}{|l|}{$n(\%)$} & \multirow{2}{*}{$\begin{array}{l}\text { Model } \\
\text { CC + TC vs TT }\end{array}$} & \multirow{2}{*}{$\frac{\boldsymbol{p}}{0.33}$} & \multirow{2}{*}{$\frac{\text { OR }}{0.54}$} & \multicolumn{2}{|l|}{$95 \% \mathrm{Cl}$} \\
\hline & TT & TC & $\mathrm{CC}$ & & & & 0.18 & 1.59 \\
\hline Pericarditis/pleuritis & $8(22.22)$ & $3(7)$ & $5(28)$ & $\mathrm{TT}+\mathrm{TC}$ vs CC & 0.18 & 2.34 & 0.7 & 7.88 \\
\hline Without pericarditis/pleuritis & $28(77.78)$ & $39(93)$ & $13(72)$ & $\mathrm{CC}+\mathrm{TT}$ vs TC & 0.03 & 0.24 & 0.06 & 0.92 \\
\hline Allele & $\mathbf{T}$ & $\mathrm{C}$ & & CC vs TT & 0.6532 & 1.35 & 0.37 & 4.92 \\
\hline Pericarditis/pleuritis & $19(17)$ & $13(17)$ & & TC vs TT & 0.0687 & 0.27 & 0.07 & 1.11 \\
\hline Without pericarditis/pleuritis & $95(83)$ & $65(83)$ & & T vs $C$ & 1 & 1 & 0.46 & 2.17 \\
\hline
\end{tabular}

$n$ number of patients with clinical information; $p$ value $<0.05$ is considered significant, indicated in bold; $p$ value obtained from $\chi^{2}$ or Fisher exact test 
miR143_rs713147

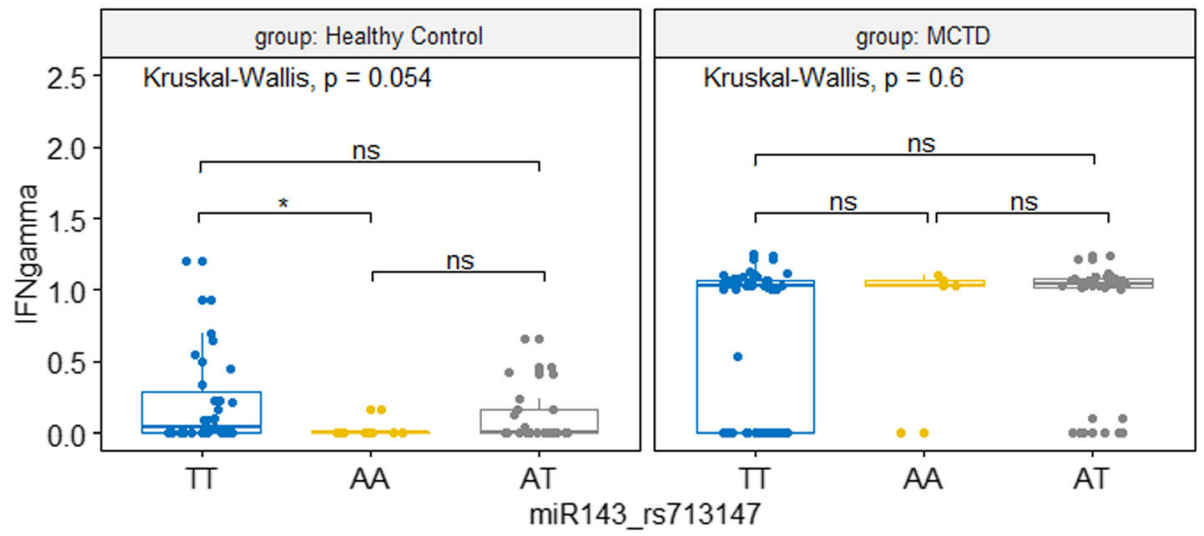

Fig. $1 \mathrm{IFN}-\gamma$ serum concentration between miR-143 rs713147 genotypes. $\mathrm{HC}$ group $\left(\mathrm{N}_{\mathrm{AA}}=10, \mathrm{~N}_{\mathrm{AT}}=25, \mathrm{~N}_{T T}=31\right)$; $\mathrm{MCTD}$ group $\left(\mathrm{N}_{\mathrm{AA}}=5\right.$, $\left.\mathrm{N}_{\mathrm{AT}}=34, \mathrm{~N}_{\mathrm{TT}}=55\right)$. ns: $p>0.05 ;{ }^{*} p \leq 0.05 ;{ }^{* *} p \leq 0.01 ;{ }^{* * *} p \leq 0.001 ;{ }^{* * *} p \leq 0.0001$; IFNgamma, IFN $\gamma$ concentration in serum

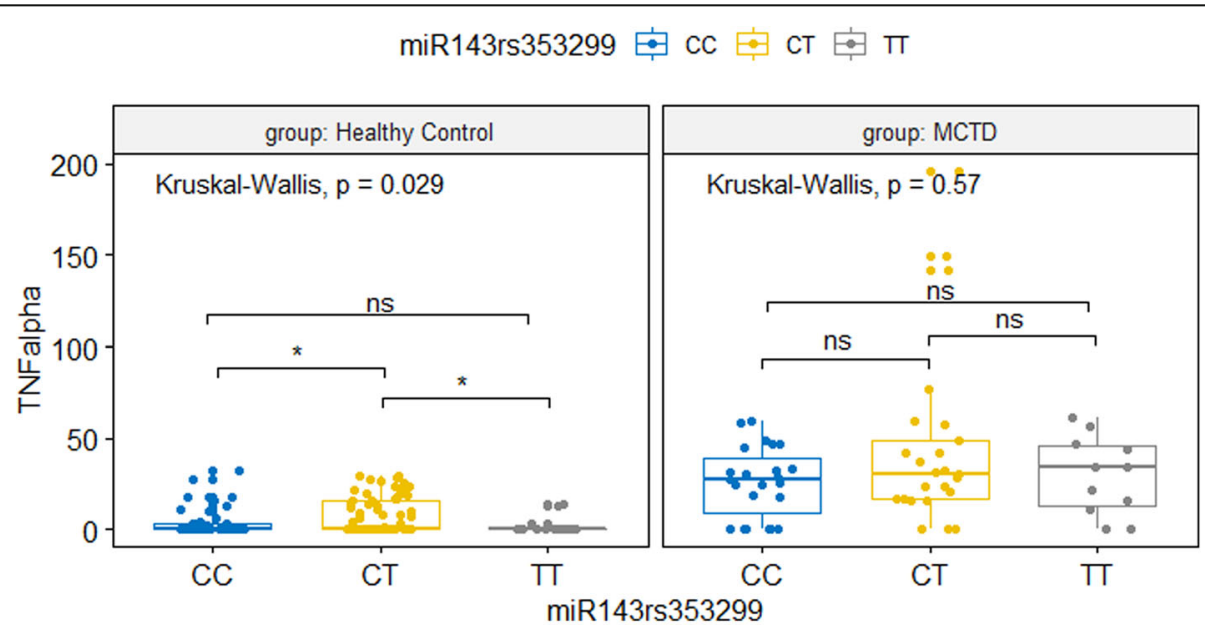

miR143rs353298 AA AG
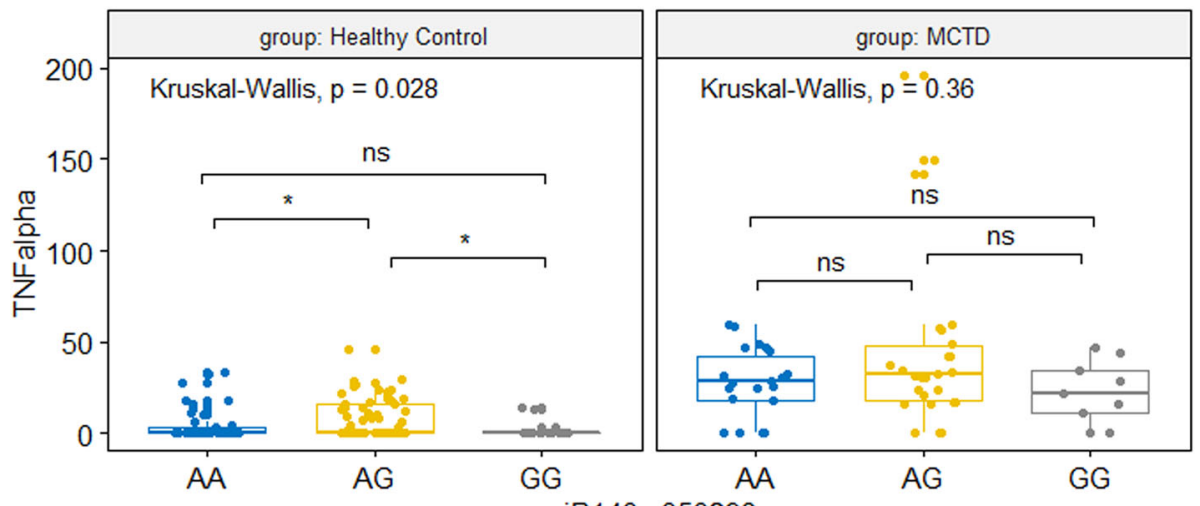

Fig. 2 TNF-alpha serum concentration between miR-143 genetic variants. Upper plot: miR-143 rs353299 control group ( $N_{C C}=47, N_{C T}=66$, $\left.N_{T T}=15\right)$; MCTD group $\left(N_{C C}=23, N_{C T}=25, N_{T T}=11\right)$; bottom plot: miR-143 rs353298 control group $\left(N_{A A}=46, N_{A G}=67, N_{G G}=14\right) ; M C T D$ $\operatorname{group}\left(\mathrm{N}_{\mathrm{AA}}=22, \mathrm{~N}_{\mathrm{AG}}=26, \mathrm{~N}_{\mathrm{GG}}=9\right) ; \mathrm{ns}: p>0.05 ;{ }^{*} p \leq 0.05 ;{ }^{* *} p \leq 0.01 ;{ }^{* *} p \leq 0.001 ;{ }^{* * * *} p \leq 0.0001 ;$ TNFalpha, TNF-a concentration in serum 
the results and determine the low power of the study. The fact that MCTD is a rare complex disease makes the recruitment of a large sample size challenging. We also have to address the fact that our analysis was not normalized by all confounders. Moreover, testing of expression in serum instead of sorted specific cell lines may "dilute" cell-specific expression pattern. On the other hand, miRNAs located in tissues and body fluids like plasma or serum make them potential "blood-based biomarkers" of disease development or in predicting therapeutic responses. Nevertheless, expression research should be continued with a larger homogeneous group of patients in the same phase of the disease to be able to state unambiguous conclusions. Functional studies are necessary to provide a direct link between these miRNA and MCTD pathogeneses. Moreover, not only healthy controls but patients with different autoimmune disorders should be included in the study.

The MCTD disease entity is still a big challenge for clinicians in diagnosing and treating patients. Its rare occurrence and patient diversity additionally hinder research and thus a better understanding of the underlying cause of this disease. We believe that our study can be used as a base, or as part of a larger study or metaanalysis, which will show the differences or similarities between MCTD and other ACTDs, which in the future will allow us to unequivocally state the existence or exclusion of MCTD as a separate disease entity and facilitate its diagnosis.

\section{Conclusion}

In conclusion, our study adds novel information in explaining the genetic and epigenetic predisposition among MCTD patients. We present preliminary association studies which indicate miR-146a and miR-143 as potential factors related to this disease. We believe that our findings may help in understanding the genetics and epigenetics of autoimmune processes not only in MCTD but also in other autoimmune diseases. However, we emphasize that these studies can provide only a direction for further research or be a comparison for similar, bigger studies of this rare disease entity.

\section{Supplementary Information}

The online version contains supplementary material available at https://doi. org/10.1186/s13075-020-02403-9.

Additional file 1.

\section{Acknowledgements}

The technical assistance of Wieslawa Frankowska is gratefully acknowledged. We are also grateful to all of the MCTD patients and healthy subjects whose cooperation made this study possible.

\section{Authors' contributions}

BS designed and performed the experiments, performed the statistical analysis, and wrote the paper. AL recruited the patients and contributed to the acquisition of data and revising of the article. AFG recruited the patients and contributed to the acquisition of data and revising of the article. MO recruited the patients and contributed to the acquisition of data and revising of the article. APG designed the experiments, monitored the acquisition of data, and revised the article. All authors read and approved the final manuscript

\section{Funding}

This work was supported by a grant from the Polpharma Scientific Foundation.

\section{Availability of data and materials}

The datasets used and/or analyzed during the current study are available from the corresponding author on reasonable request.

\section{Ethics approval and consent to participate}

All participants signed informed written consent for participation in the study. The study was approved by the ethics committee in the National Institute of Geriatrics Rheumatology and Rehabilitation, Warsaw, Poland.

Consent for publication

Not applicable.

\section{Competing interests}

The authors declare that they have no competing interests.

\section{Author details}

'Department of Molecular Biology, National Institute of Geriatrics, Rheumatology, and Rehabilitation, Spartańska 1, 02-637 Warsaw, Poland. ${ }^{2}$ Department of Connective Tissue Diseases, National Institute of Geriatrics, Rheumatology, and Rehabilitation, Spartanska 1, Warsaw 02-637, Poland.

Received: 23 April 2020 Accepted: 22 December 2020

Published online: 11 January 2021

\section{References}

1. Kasukawa R. Mixed connective tissue disease. Intern Med. 1999;38:38693 Available from: http://www.ncbi.nlm.nih.gov/pubmed/10397074. [cited 2018 Oct 16].

2. Pepmueller PH. Undifferentiated connective tissue disease, mixed connective tissue disease, and overlap syndromes in rheumatology. Mo Med. 2016;113:136-40 Available from: http://www.ncbi.nlm.nih.gov/ pubmed/27311225. [cited 2018 Oct 17].

3. O'Connell RM, Rao DS, Chaudhuri AA, Baltimore D. Physiological and pathological roles for microRNAs in the immune system. Nat Rev Immunol. 2010;10:111-22 Available from: http://www.nature.com/articles/nri2708. [cited 2018 Oct 18].

4. Baulina NM, Kulakova OG, Favorova OO. MicroRNAs: the role in autoimmune inflammation. Acta Naturae. 2016;8:21-33 Available from: http://www.ncbi. nlm.nih.gov/pubmed/27099782. [cited 2018 Aug 25].

5. Wang Z, Lu Q, Wang Z. Epigenetic alterations in cellular immunity: new insights into autoimmune diseases. Cell Physiol Biochem. 2017;41:64560 Available from: http://www.ncbi.nlm.nih.gov/pubmed/28214857. [cited 2018 Oct 18].

6. Zhang H, Huang X, Ye L, Guo G, Li X, Chen C, et al. B cell-related circulating microRNAs with the potential value of biomarkers in the differential diagnosis, and distinguishment between the disease activity and lupus nephritis for systemic lupus erythematosus. Front Immunol. 2018;9:1473 Available from: http://www.ncbi.nlm.nih.gov/pubmed/3 0008716. [cited 2018 Sep 2].

7. Moosavi A, Motevalizadeh Ardekani A. Role of epigenetics in biology and human diseases. Iran Biomed J. 2016;20:246-58 Available from: http://www. ncbi.nlm.nih.gov/pubmed/27377127. [cited 2018 Oct 18].

8. Husakova M. MicroRNAs in the key events of systemic lupus erythematosus pathogenesis. Biomed Pap. 2016;160:327-42 Available from: http://www. ncbi.nlm.nih.gov/pubmed/27003314. [cited 2018 Sep 2].

9. Paraboschi EM, Soldà G, Gemmati D, Orioli E, Zeri G, Benedetti MD, et al. Genetic association and altered gene expression of mir-155 in multiple 
sclerosis patients. Int J Mol Sci. 2011;12:8695-712 Available from: http:// www.ncbi.n/m.nih.gov/pubmed/22272099. [cited 2018 Apr 23].

10. Boldin MP, Taganov KD, Rao DS, Yang L, Zhao JL, Kalwani M, et al. miR-146a is a significant brake on autoimmunity, myeloproliferation, and cancer in mice. J Exp Med. 2011;208:1189-201 Available from: http://www.ncbi.nlm. nih.gov/pubmed/21555486. [cited 2018 Oct 25].

11. Qu B, Cao J, Zhang F, Cui H, Teng J, Li J, et al. Type I interferon inhibition of MicroRNA-146a maturation through up-regulation of monocyte chemotactic protein-induced protein 1 in systemic lupus erythematosus. Arthritis Rheumatol. 2015;67:3209-18 Available from: http://doi.wiley.com/1 0.1002/art.39398. [cited 2018 Sep 2].

12. Tang $Y$, Luo $X$, Cui H, Ni X, Yuan M, Guo Y, et al. MicroRNA-146a contributes to abnormal activation of the type I interferon pathway in human lupus by targeting the key signaling proteins. Arthritis Rheum. 2009;60:1065-75 Available from: http://doi.wiley.com/10.1002/art.24436. [cited 2018 Sep 2].

13. Li B, Wang X, Choi IY, Wang Y-C, Liu S, Pham AT, et al. miR-146a modulates autoreactive Th17 cell differentiation and regulates organ-specific autoimmunity. J Clin Invest. 2017;127:3702-16 Available from: https://www. jci.org/articles/view/94012. [cited 2018 Oct 31].

14. Dai R, Phillips RA, Zhang Y, Khan D, Crasta O, Ahmed SA. Suppression of LPS-induced Interferon-gamma and nitric oxide in splenic lymphocytes by select estrogen-regulated microRNAs: a novel mechanism of immune modulation. Blood. 2008;112:4591-7 Available from: http://www.ncbi.nlm. nih.gov/pubmed/18791161. [cited 2018 Oct 24].

15. Wang G, Tam L-S, Li EK-M, Kwan BC-H, Chow K-M, Luk CC-W, et al. Serum and urinary cell-free MiR-146a and MiR-155 in patients with systemic lupus erythematosus. J Rheumatol. 2010;37:2516-22 Available from: http://www. ncbi.nlm.nih.gov/pubmed/20952466. [cited 2018 Oct 24].

16. Tili E, Michaille J-J, Cimino A, Costinean S, Dumitru CD, Adair B, et al. Modulation of miR-155 and miR-125b levels following lipopolysaccharide/ TNF-alpha stimulation and their possible roles in regulating the response to endotoxin shock. J Immunol. 2007;179:5082-9 Available from: http://www. ncbi.nlm.nih.gov/pubmed/17911593. [cited 2018 Nov 11].

17. Wang D, Tang M, Zong P, Liu H, Zhang T, Liu Y, et al. MiRNA-155 regulates the Th17/Treg ratio by targeting SOCS1 in severe acute pancreatitis. Front Physiol. 2018;9:686 Available from: http://www.ncbi.nlm.nih.gov/pubmed/2 9937734. [cited 2018 Nov 16]

18. Rajasekhar M, Olsson AM, Steel KJA, Georgouli M, Ranasinghe U, Brender Read C, et al. MicroRNA-155 contributes to enhanced resistance to apoptosis in monocytes from patients with rheumatoid arthritis. J Autoimmun. 2017;79:53-62 Available from: http://www.ncbi.nlm.nih.gov/ pubmed/28118944. [cited 2018 Nov 16]

19. Zheng $Y, G e$ W, Ma Y, Xie G, Wang W, Han L, et al. miR-155 regulates IL-10producing CD24hiCD27+ B cells and impairs their function in patients with Crohn's disease. Front Immunol. 2017:8:914 Available from: http://www.ncbi. nlm.nih.gov/pubmed/28824639. [cited 2018 Nov 16].

20. Li C, Fu W, Zhang Y, Zhou L, Mao Z, Lv W, et al. Meta-analysis of microRNA-146a rs2910164 G>C polymorphism association with autoimmune diseases susceptibility, an update based on 24 studies. Plos One. 2015;10:e0121918 Available from: http//www.ncbi.nlm.nih.gov/pubmed/25830862. [cited 2018 Oct 25].

21. Løvendorf MB, Zibert JR, Gyldenløve M, Røpke MA, Skov L. MicroRNA-223 and miR-143 are important systemic biomarkers for disease activity in psoriasis. J Dermatol Sci. 2014;75:133-9 Available from: http://www.ncbi.nIm. nih.gov/pubmed/24909097. [cited 2018 Oct 25].

22. Liu X, Gong J, Xu B. miR-143 down-regulates TLR2 expression in hepatoma cells and inhibits hepatoma cell proliferation and invasion. Int J Clin Exp Pathol. 2015;8:12738-47 Available from: http://www.ncbi.nlm.nih.gov/ pubmed/26722463. [cited 2018 Nov 14].

23. Guo H, Chen Y, Hu X, Qian G, Ge S, Zhang J. The regulation of Toll-like receptor 2 by miR-143 suppresses the invasion and migration of a subset of human colorectal carcinoma cells. Mol Cancer. 2013;12:-77 Available from: http://www.ncbi.nlm.nih.gov/pubmed/23866094. [cited 2018 Nov 14].

24. Yuan F, Sun R, Li L, Jin B, Wang Y, Liang $Y$, et al. A functional variant rs353292 in the flanking region of miR-143/145 contributes to the risk of colorectal cancer. Sci Rep. 2016;6:30195 Available from: http://www.ncbi. nlm.nih.gov/pubmed/27444415. [cited 2018 Nov 14].

25. Jin Y-P, Hu Y-P, Wu X-S, Wu Y-S, Ye Y-Y, Li H-F, et al. miR-143-3p targeting of ITGA6 suppresses tumour growth and angiogenesis by downregulating PLGF expression via the PI3KJAKT pathway in gallbladder carcinoma. Cell Death Dis. 2018;9:182 Available from: http://www.ncbi.n/m.nih.gov/ pubmed/29416013. [cited 2018 Nov 14].
26. Chang L, Zhang D, Shi H, Bian Y, Guo R. MiR-143 inhibits endometrial cancer cell proliferation and metastasis by targeting MAPK1. Oncotarget. 2017:8:84384-95 Available from: http://www.ncbi.nlm.nih.gov/pubmed/2913 7432. [cited 2018 Nov 14].

27. Mao Y, Liu J, Zhang D, Li B. miR-143 inhibits tumor progression by targeting FAM83F in esophageal squamous cell carcinoma. Tumor Biol. 2016;37:900922 Available from: http://link.springer.com/10.1007/s13277-015-4760-9. [cited 2018 Nov 15].

28. Zhou LL, Dong JL, Huang G, Sun ZL, Wu J. MicroRNA-143 inhibits cell growth by targeting ERK5 and MAP3K7 in breast cancer. Brazilian J Med Biol Res 2017:50:e5891. Available from: http://www.ncbi.nlm.nih.gov/pubmed/2 8746466. [cited 2018 Nov 14].

29. Tomczak M, Tomczak E. The need to report effect size estimates revisited. An overview of some recommended measures of effect size. Trends Sport Sci. 2014;1:19-25 Available from: http://www.wbc.poznan.pl/Content/32586 7/5_Trends_Vol21_2014_no1_20.pdf.

30. Saba R, Sorensen DL, Booth SA. MicroRNA-146a: a dominant, negative regulator of the innate immune response. Front Immunol. 2014;5:578 Available from: http://www.ncbi.nlm.nih.gov/pubmed/25484882. [cited 2019 Sep 15].

31. Jazdzewski K, Murray EL, Franssila K, Jarzab B, Schoenberg DR, de la Chapelle A. Common SNP in pre-miR-146a decreases mature miR expression and predisposes to papillary thyroid carcinoma. Proc Natl Acad Sci. 2008;105:7269-74 Available from: http://www.ncbi.nlm.nih.gov/ pubmed/18474871. [cited 2018 Oct 10].

32. Li C, Fu W, Zhang Y, Zhou L, Mao Z, Lv W, et al. Meta-analysis of microRNA146a rs2910164 G>C polymorphism association with autoimmune diseases susceptibility, an update based on 24 studies. Han W, editor. Plos One 201510:e0121918. Available from: http://dx.plos.org/10.1371/journal.pone. 0121918. [cited 2018 Oct 10].

33. Shao Y, Li J, Cai Y, Xie Y, Ma G, Li Y, et al. The functional polymorphisms of miR-146a are associated with susceptibility to severe sepsis in the chinese population. Mediators Inflamm. 2014, 2014:1-10 Available from: http://www. ncbi.n/m.nih.gov/pubmed/24701036. [cited 2018 Oct 10].

34. Niu Z, Wang J, Zou H, Yang C, Huang W, Jin L. Common MIR146A polymorphisms in Chinese ankylosing spondylitis subjects and controls. Antoniou AN, editor Plos One 2015;10:e0137770. Available from: http://dx. plos.org/10.1371/journal.pone.0137770. [cited 2018 Oct 10].

35. Guo Z, Maki M, Ding R, Yang Y, Zhang B, Xiong L, et al. Genome-wide survey of tissue-specific microRNA and transcription factor regulatory networks in 12 tissues. Sci Rep. 2014;4:799-804 Available from: http://www. nature.com/articles/srep05150.[cited 2016 Dec 21].

\section{Publisher's Note}

Springer Nature remains neutral with regard to jurisdictional claims in published maps and institutional affiliations.
Ready to submit your research? Choose BMC and benefit from:
- fast, convenient online submission
- thorough peer review by experienced researchers in your field
- rapid publication on acceptance
- support for research data, including large and complex data types
- gold Open Access which fosters wider collaboration and increased citations
- maximum visibility for your research: over $100 \mathrm{M}$ website views per year
At BMC, research is always in progress.
Learn more biomedcentral.com/submissions 